\title{
BILIOPANCREATIC DIVERSION WITH DUODENAL SWITCH. LONG TERM WEIGHT LOSS
}

\author{
Toni I. Stoyanov, \\ Pedro C. Sanchez, \\ Antonio P. Calero, \\ Augustina M. Moreno, \\ Emilio G. Blazquez, \\ Servando U. Rebollo, \\ Casado Santamaria $P$., \\ Pencho T. Tonchev', \\ Kaloyan T. Ivanov', \\ Dimitar J. Stoikov
}

\section{Section of Endocrine and Bariatric Surgery, Department of General Surgery, University Hospital Center Albacete, Spain \\ Department of Surgery, Medical University - Pleven, Bulgria}

\begin{abstract}
Summary
Biliopancreatic derivation with duodenal switch (BPDDS) as an operative technique in the management of morbid obesity was created as an alternative to BPD (Scopinaro's operation), because of BPD-DS's fewer malabsorption side effects, better restrictive effect to the stomach remnant, fewer peptic ulcers and dumping syndromes, as well as lower morbidity and mortality rate. Between January 2003 and June 2012 in the University Hospital Center of Albacete, 141 patients with morbid obesity underwent BPD-DS. The patients were divided in groups according to four criteria: length of the common channel, age, gender and initial Body Mass Index. On the $6^{\text {th }}$ postoperative year in our study the percent of excessive body weight loss was $67.6 \%$ and the percentage of excessive BMI loss was $73 \%$. According to the evaluation announced by Hess D.S. \& Hess D.W, our results could be assessed as successful after 6 months, good on the first year, excellent on the second, and good from $3^{\text {rd }}$ to $9^{\text {th }}$ postoperative years. Our results confirm the hypothesis that the biliopancreatic derivation with duodenal switch is a bariatric intervention, which leads to a significant weight loss, well preserved in time.
\end{abstract}

Key word: duodenal switch, obesity, metabolic syndrome, bariatric surgery

\section{Introduction}

Morbid obesity is a disease, incurable through diet and medication. Various diets show satisfactory outcome only for a short period of time and are ineffective in maintaining long term weight loss. In such patients, surgical treatment alone can help achieve significant weight loss, which remains stable in time $[1,2]$.

Biliopancreatic derivation with duodenal switch (BPD-DS; Figure 1) as an operative technique in the management of morbid obesity was created as an alternative to BPD (Scopinaro's operation; Figure 2), because of BPD-DS's fewer malabsorption side effects, better restrictive effect to the stomach remnant, fewer peptic ulcers and dumping syndromes, as well as lower morbidity and mortality rates [3]. 


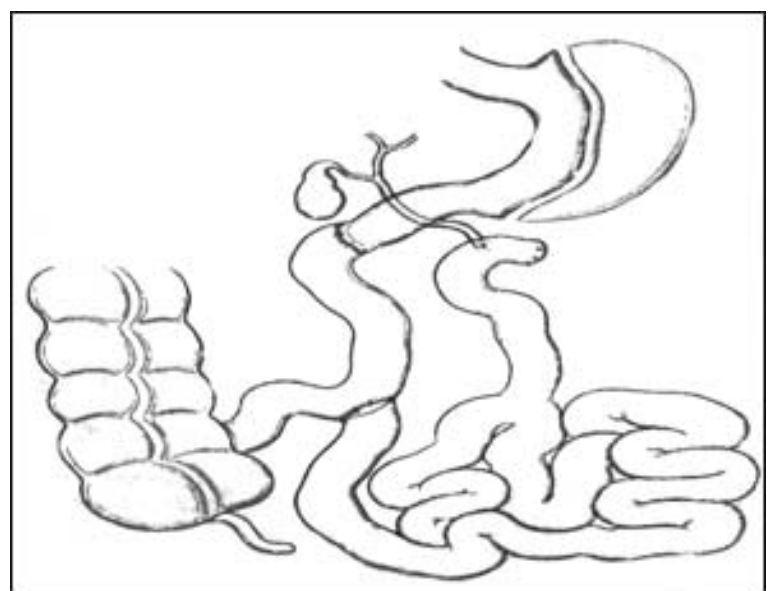

Figure 1. Biliopancretic diversion with duodenal swith

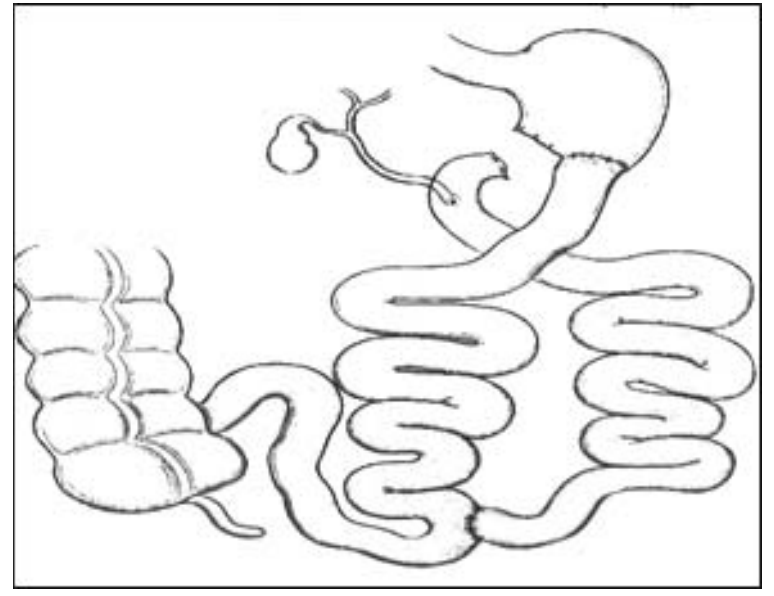

Figure 2. Biliopancretic diversion (Scopinaro type)

Many authors consider BPD-DS to be a strictly malabsorption technique. However, in contrast to BPD, which practically does not considerably change the reservoir function of the stomach, DS includes significant stomach resection, leaving a small-volume tube. The anatomy of the minor curvature of the stomach is characterized by a resistant transverse smooth muscle layer and the ability of the stomach remnant to relax after feeding is very limited. That is why this bariatric procedure includes a major restrictive part. Many surgeons who execute sleeve gastrectomy in a single act operation leave the stomach tube narrower than in BPD-DS [4]. Clinical studies investigating food intake of patients with BPD-DS have shown that it is 30\% to $50 \%$ reduced as compared to preoperative intake [5].

\section{Material and Methods}

Between January 2003 and June 2012, 141 patients with morbid obesity underwent BPD-DS in the University Hospital Center of Albacete. Table 1 shows the main characteristics of patients.

Of the 141 patients, 128 were operated on conventionally and 13 - laparoscopically. In all conventional operations, the incision was transversal supraumbilical laparotomy, which allowed good intraoperative exposition and reduced postoperative pain. In the group of patients operated on laparoscopically, 6 ports were used compulsory, and only in exceptional cases because of technical difficulties, a $7^{\text {th }}$ port was placed.

All patients were operated on under general anesthesia. The anesthesiologic risk was evaluated by the ASA score. The lowest recorded ASA score was 1 and the highest - 4, i.e. 2.7 on average. Anaesthesiologic complications did not occur intraoperatively, nor did they develop in the early or late postoperative period.

Postoperatively, all patients were included in follow up as follows: on 3rd and 6th postoperative month and then every year. Weight loss, BMI, major comorbidities and all important vitamins and microelement levels were measured and supplemented if needed.

Weight loss and all major derivatives as BMI, percent of Excess Weight Loss, percent of Excess BMI Loss, percent of Expected BMI were calculated according to accepted formulas (Table 2) and analyzed for dependencies on sex, initial BMI group, initial age group, common channel group, and time [6,7].

Statistical analysis was done using a mixed model approach with SPSS statistical program. All $p$-values were two-sided and those under 0.05 were considered statistically significant.

\section{Results}

The preoperative body weight of patients, distributed by gender and age, is shown on tables 3 and 4 . 
Table 1. Main characteristics of studied group

\begin{tabular}{|c|c|c|c|c|}
\hline & & $\mathrm{N}$ & mean & Range \\
\hline \multicolumn{5}{|l|}{ Sex: } \\
\hline • & Male & $40(28.4 \%)$ & & \\
\hline & Female & $101(71.6)$ & & \\
\hline Age & & 141 & 41.8 & $21-60$ \\
\hline$\bullet$ & $<25 y$ & 6 & & \\
\hline & $26-45 y$ & 82 & & \\
\hline$\bullet$ & $45-65 y$ & 53 & & \\
\hline weight & & 141 & 139.13 & $100-193 \mathrm{~kg}$ \\
\hline height & & 141 & 163.2 & $141-192 \mathrm{~cm}$ \\
\hline BMI & & 141 & $51.91 \mathrm{~kg} / \mathrm{m}^{2}$ & $41.6-75.1 \mathrm{~kg} / \mathrm{m}^{2}$ \\
\hline & $40-60 \mathrm{~kg} / \mathrm{m}^{2}$ & $98 \quad(69.5)$ & & \\
\hline & $>60 \mathrm{~kg} / \mathrm{m}^{2}$ & $43(30.5 \%)$ & & \\
\hline
\end{tabular}

Length of the common channel:

- $\quad 50 \mathrm{~cm}$ common channel

- $\quad 75 \mathrm{~cm}$ common channel

Table 2. Formulas used for calculating the parameters

\begin{tabular}{|c|c|}
\hline $\begin{array}{l}\text { Excess Body Mass } \\
\text { Index }\end{array}$ & $\mathrm{EBMI}=\mathrm{BMI}-25$ \\
\hline \% Excess Weight Loss & $\begin{array}{l}\text { \% EWL }=\frac{\text { actual body weight }}{\text { actual body weight }- \text { Ideal body weight }} * \mathbf{1 0 0 .} \\
\text { (Ideal weight : (Based on tables of Metropolitan Life Insurance, New York, } 1940 \text { : } \\
\text { •Female: } 152 \mathrm{~cm}, 54.09 \mathrm{~kg} . \text { For every } 2.54 \mathrm{~cm} \text { height add } 1.36 \mathrm{~kg} . \\
\text { •Male: } 159.6 \mathrm{~cm}, 61.36 \text { кг. For every } 2.54 \mathrm{~cm} \text { height add } 1.36 \mathrm{~kg} . \text { ) }\end{array}$ \\
\hline $\begin{array}{l}\text { \% Excess Body Mass } \\
\text { Index Lost }\end{array}$ & $\% \mathrm{EBMIL}=\frac{\text { BMI initial }- \text { BMI final }}{\text { BMI initial }-25} * 100$ \\
\hline $\begin{array}{l}\text { Expected BMI after } \\
\text { bariatric surgery }\end{array}$ & $\% \mathrm{EBMI}=\frac{\text { BMI initial-BMI final }}{\mathrm{BMI} \text { initial }-(0.33 \mathrm{BMI} \text { initial }+14)} * 100$ \\
\hline
\end{tabular}

Table 3. Average preoperative body weight by gender

\begin{tabular}{llll}
\hline & male & Female & $\mathrm{p}$ \\
\hline Weight & 157.23 & 131.95 & $<0.05$ \\
mean \pm SD & $( \pm 17.89)$ & $( \pm 16.66)$ & \\
\cline { 1 - 2 } $\mathrm{N}$ & 40 & 101 & \\
\hline
\end{tabular}


Table 4. Average preoperative body weight by age

\begin{tabular}{lllll}
\hline Age group & $<25$ years & $26-45$ years & $46-65$ years & $p$ \\
\hline $\begin{array}{l}\text { W eight } \\
\text { mean } \pm \text { SD }\end{array}$ & $156.83( \pm 14.93)$ & $142.99( \pm 20.82)$ & $131.13( \pm 17.34)$ & $<0.05$ \\
\hline $\mathrm{N}$ & 6 & & & \\
\hline
\end{tabular}

Table 5 shows that excessive weight loss and excessive BMI loss on the $6^{\text {th }}$ postoperative month was more than $50 \%$. The biggest weight loss was observed on the second year: EWL$78.9 \%$ and EBMIL-85.6\% (Figure 3). Eventually, these indexes showed a tendency to drop in time, but they stayed stable over $50 \%$, and on the ninth year reached $64.4 \%$ of EWL-and $70.7 \%$ of EBMIL. Average body mass and BMI were also at their lowest on the second year: $77.5 \mathrm{~kg}$ and $28.8 \mathrm{~kg} / \mathrm{m}^{2}$ respectively, after which they rose, so that on the ninth year they reached $89.4 \mathrm{~kg}$ and $29 \mathrm{~kg} / \mathrm{m}^{2}$ respectively. Baltasar's EBMI was $101.7 \%$ on the first year, remained over $100 \%$ till the fourth year, and also peaked on the second year at $110.1 \%$. On the ninth year the EBMI was $90.4 \%$.

Results from mixed model analysis of changes of weight and BMI with time and different factors as initial BMI, age group, gender and length of common channel are presented in Figure 4.

Table 5. Changes of body weight and calculated indexes

\begin{tabular}{|c|c|c|c|c|c|c|c|c|c|c|c|c|}
\hline Time -years & Initial & $3 \mathrm{~m}$ & $6 \mathrm{~m}$ & $1 \mathrm{y}$ & $2 y$ & $3 y$ & $4 y$ & $5 y$ & $6 y$ & $7 y$ & $8 \mathrm{y}$ & $9 y$ \\
\hline Body weight & 139.1 & 114.3 & 98.4 & 82.6 & 77.6 & 79.9 & 81.9 & 83.1 & 85.3 & 86.2 & 86.5 & 89.4 \\
\hline $\begin{array}{l}\text { \%Excess } \\
\text { Weight Loss }\end{array}$ & & $32 \%$ & $52.6 \%$ & $72.8 \%$ & $78.9 \%$ & $75.7 \%$ & $72 \%$ & $70.1 \%$ & $67.6 \%$ & $66.8 \%$ & $65.1 \%$ & $64.4 \%$ \\
\hline BMI & 51.9 & 42.6 & 36.7 & 30.7 & 28.8 & 29.7 & 30.7 & 31.3 & 32.1 & 32.5 & 31.7 & 29.0 \\
\hline $\begin{array}{l}\text { \% Excess } \\
\text { BMI Loss }\end{array}$ & & $34.8 \%$ & $57.1 \%$ & $79.1 \%$ & $85.6 \%$ & $82.2 \%$ & $78.1 \%$ & $78 \%$ & $73 \%$ & $71.9 \%$ & $70.4 \%$ & $70.7 \%$ \\
\hline $\begin{array}{l}\% \text { Expected } \\
\text { BMI }\end{array}$ & & $44.7 \%$ & $73.4 \%$ & $101.7 \%$ & $110.1 \%$ & $105.8 \%$ & $100.6 \%$ & $98 \%$ & $94.5 \%$ & $93.5 \%$ & $90.9 \%$ & $90.4 \%$ \\
\hline
\end{tabular}

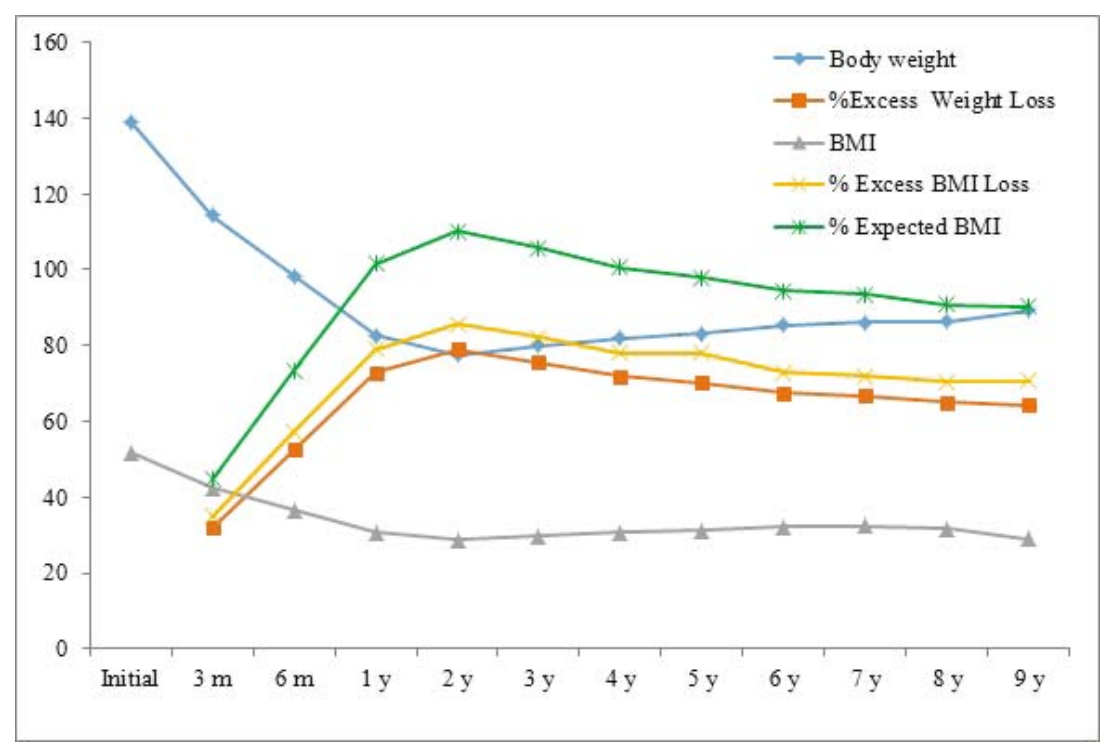

Figure 3. Body weight loss. (Data in table 5) 

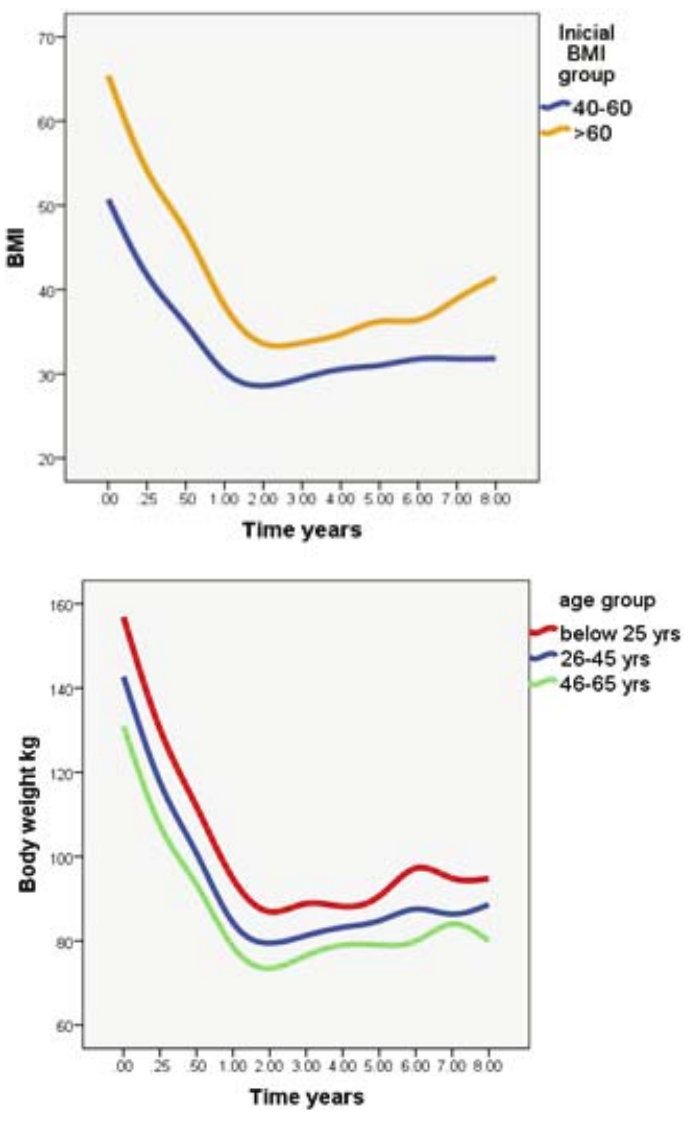
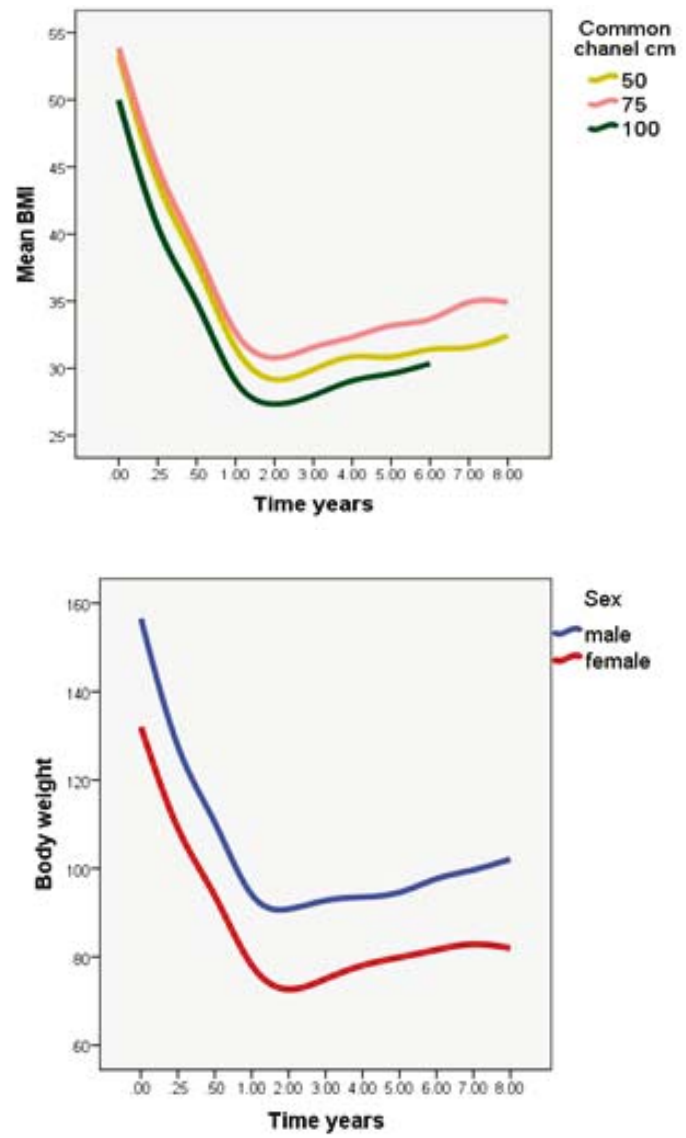

Figure 4. Body weight loss in groups by initial BMI $(p=0.020)$, common channel $(p=0.752)$, age $(p=0.752)$ and gender $(\mathrm{p}=0.933)$

\section{Discussion}

Chronologically, in the 'length of common channel' group statistically significant correlation between body weight loss and the length of the common channel was not found $(\mathrm{p}=0.752)$. Neither in the age $(\mathrm{p}=0.947)$ nor in the gender group $(\mathrm{p}=0.933)$ was such correlation discovered.

Solely in the group by initial BMI there was a statistically significant difference in the body weight loss in time. Patients with higher initial BMI lost less body weight and lost it more slowly in time.

The value of Baltasar's expected BMI aims to prove that the goal of bariatric interventions is not to reach perfect BMI $\left(25 \mathrm{~kg} / \mathrm{m}^{2}\right)$ in all patients, especially in patients with $\mathrm{BMI}>50 \mathrm{~kg} / \mathrm{m}^{2}$. The goal is to achieve levels of expected BMI around $100 \%$, results above $100 \%$ are considered excellent, and below $100 \%$ are considered as an improvement [6]. Analyzing a group of 1321 patients, Baltasar concluded that the achieved good and excellent results should not always be considered in comparison with excessive BMI loss, which is a function of the ideal BMI. Rather, they should be reviewed in each patient -as the so-called expected BMI [7]. In other words, the goal of the bariatric intervention is not perfect body weight. The author has reported that the excessive BMI loss in different operative techniques is as follows: gastric band $-55 \%$, gastric bypass $-65 \%$, BPD-DS $>70 \%$. He has also stated that the expected BMI is applicable to evaluate the results of different techniques, hospital centers and surgeons.

Two randomized clinical trials, conducted in bariatric centers in Chicago and Portland, compared the results in body weight loss in patients with DS and stomach bypass. Some authors did not find differences in weight loss, while others reported better weight loss in patients with excessive obesity (BMI>50) after BPD-DS, as compared to stomach bypass. Both studies indicated a tendency to choose DS in patients with more severe forms of obesity and 
metabolic comorbidities. The clinical trial in Portland followed up the patients for 2 years and reported a longer hospitalization with DS, higher risk of suture insufficiency, and almost equal mortality rate $(0.8 \%$ for DS against $0.9 \%$ for stomach bypass). The excessive weight loss was $67 \%$ for stomach bypass and $64 \%$ for DS after 2 years [8].

In a clinical study in Chicago, hospitalization was also slightly longer in BPD-DS. Mortality rate was low in both groups $(0.05 \%$ in BPD-DS against $0 \%$ in stomach bypass), but in the DS group the excessive body weight loss was higher than in the stomach bypass group (72\% against $60 \%$ ) after 2 years and with a tendency to rise after the third year in both groups [9].

In the Portland trial, only 93 patients out of 350 were followed up after the second year, and in the Chicago trial 65 out of 350 patients were followed up after the third year. In conclusion, the weight loss results from BPD-DS and stomach bypass are comparable, with a small advantage for BPD-DS in patients with severe obesity.

Similar results, comparing BPD-DS and Roux-en-Y gastric bypass (RYGB), were reported by Dorman RB et al. in 178 patients with BPD-DS and 139 with RYGB. The author reported a statistically significant improvement of diabetes type 2, arterial hypertension and dyslipidemia in both groups, but it was considerably higher in the BPD-DS group. The body weight loss was equal in both groups. Diarrhea and feeling of abdomen swelling was more frequent in the BPD-DS group [10].

In our clinical study, preoperative values of body weight showed a statistically significant correlation in the groups matched for body weight/gender $(p=0.000)$ in favor of the male group and the group matched for body weight/age, in which the patients below 25 years of age were with the highest values of body weight and BMI $(p=0.000)$. The speed of weight loss postoperatively was the same in all the groups and did not show statistical significance $(\mathrm{p}=0.752)$. Only in the initial BMI group there was a significant difference in weight loss in time, which indicated that patients with initially higher BMI lost less body weight and this loss occurred more slowly $(\mathrm{p}=0.020)$.

The absolute values of average body weight in the groups of patients with different length of the common channel were at their lowest on the second year after the intervention. The lowest average body weight was found in the $100 \mathrm{~cm}$ group and the highest - in the $75 \mathrm{~cm}$ group. This tendency was preserved the same up to the $6^{\text {th }}$ year of the study.

Table 6. Results according to $\%$ EWL by Hess D.S. and Hess D.W (3)

\begin{tabular}{ll}
\hline Excellent results & EWL\% $>80 \%$ \\
\hline Good results & EWL\% $-60-80 \%$ \\
\hline Satisfactory results & EWL $\%-50-60 \%$ \\
\hline Poor results & EWL $\%-20-50 \%$ \\
\hline Very poor results & EWL $\%<20 \%$ \\
\hline
\end{tabular}

Comparable results were announced by Hess D.S. \& Hess D.W.: $\%$ EWL $-80 \%$ on the $2^{\text {nd }}$ year and $75 \%$ on the $10^{\text {th }}$ year postoperatively. The authors separated the results from treatment according to the excessive body weight loss to excellent, good, satisfactory, poor, and very poor (Table 6). Only the results defined as excellent, good, and satisfactory were considered as successful [11]. Marceau reported 747 patients, who underwent BPD DS with the lowest value of body weight at $53 \mathrm{~kg}$ and regained $7 \mathrm{~kg}$ of the body weight after a few years [12].

According to this evaluation, our results can be assessed as successful after 6 months, good on the first year, excellent on the second, and good from $3^{\text {rd }}$ to $9^{\text {th }}$ postoperative year.

\section{Conclusion}

Biliopancreatic derivation with duodenal switch is a bariatric intervention, which leads to significant weight loss, well preserved with time. On the $6^{\text {th }}$ postoperative year in our study the excessive body weight loss was $67.6 \%$ and the excessive BMI loss - $73 \%$.

These outstanding results of this bariatric surgical technique were confirmed by other major studies and tended to exceed the weight loss results of other surgical techniques such as the gastric bypass.

Analyses of variations of BPD-DS revealed that the groups with different length of the common channel showed no significant difference in the weight loss concerning long term results. No such difference was found in the groups matched by sex and age. 
Only patients with initially higher BMI lost less weight and lost it more slowly. On the whole, BPD-DS turned out to be an excellent choice in the complex treatment of obese patients.

\section{References}

1. Buchwald H, Avidor Y, Braunwald E, Jensen MD, Pories W, Fahrbach K, et al. Bariatric surgery: a systematic review and meta-analysis. JAMA. 2004;292(14):1724-37.

2. Sjostrom L, Narbro K, Sjostrom CD, Karason K, Larsson B, Wedel H, et al. Effects of bariatric surgery on mortality in Swedish obese subjects. N Engl J Med. 2007;357(8):741-52.

3. Hess DS, Hess DW. Biliopancreatic diversion with a duodenal switch. Obes Surg. 1998;8(3):267-82.

4. Sanchez-Santos R, Masdevall C, Baltasar A, Martinez-Blazquez C, Garcia Ruiz de Gordejuela A, Ponsi E, et al. Short- and mid-term outcomes of sleeve gastrectomy for morbid obesity: the experience of the Spanish National Registry. Obes Surg. 2009;19(9):1203-10.

5. Anderson B, Gill RS, de Gara CJ, Karmali S, Gagner M. Biliopancreatic diversion: the effectiveness of duodenal switch and its limitations. Gastroenterol Res Pract. 2013;2013:974762.
6. Baltasar A, Serra C, Bou R, Bengochea M, Perez $\mathrm{N}$, Borras F, et al. [Expected body mass index after bariatric surgery]. Cir Esp. 2009;86(5):308-12. Spanish.

7. Baltasar A, Bou R, Bengochea M, Serra C, Perez $\mathrm{N}$. [One thousand bariatric interventions].Cir Esp. 2006;79(6):349-55. Spanish.

8. Deveney CW, MacCabee D, Marlink K, Welker K, Davis J, McConnell DB. Roux-en-Y divided gastric bypass results in the same weight loss as duodenal switch for morbid obesity. Am J Surg. 2004;187(5):655-9.

9. Prachand VN, Davee RT, Alverdy JC. Duodenal switch provides superior weight loss in the superobese $(\mathrm{BMI}>$ or $=50 \mathrm{~kg} / \mathrm{m} 2)$ compared with gastric bypass. Ann Surg. 2006;244(4):611-9.

10. Dorman RB, Rasmus NF, al-Haddad BJ, Serrot FJ, Slusarek BM, Sampson BK, et al. Benefits and complications of the duodenal switch/biliopancreatic diversion compared to the Roux-en-Y gastric bypass. Surgery. 2012;152(4):758-65; discussion 65-7.

11. Hess DS, Hess DW, Oakley RS. The biliopancreatic diversion with the duodenal switch: results beyond 10 years. Obes Surg. 2005;15(3):408-16.

12. Marceau P, Hould FS, Simard S, Lebel S, Bourque RA, Potvin M, et al. Biliopancreatic diversion with duodenal switch. World J Surg. 1998;22(9):94754. 